Bangladesh J. Bot. 44(3): 351-358, 2015 (September)

\title{
INFLUENCE OF BREVICORYNE BRASSICAE L. INCIDENCE ON THE YIELD OF MARKETABLE CABBAGE HEADS UNDER DIFFERENT INSECTICIDE SPRAY REGIMES IN HIGHLANDS OF HIMACHAL PRADESH (INDIA)
}

\author{
Sanjay Kumar Sharma* \\ CSK HPKV, Highland Agricultural Research and Extension Centre, Kukumseri, \\ (Lahaul and Spiti), Himachal Pradesh, India-175142
}

Key words: BC ratio, Cabbage aphid, Endosulfan, Malathion, NSKE, Yield

\begin{abstract}
Strong and negative correlation was observed between the yield of marketable cabbage heads and populations of/plant infestations by cabbage aphid (Brevicoryne brassicae L.) 14 days after first and second spray. Weak correlation existed between yield of marketable cabbage heads and aphid populations/plant infestations at pre-treatment. Therefore, insecticide sprays should be done to control late aphid infestations and avoided against early aphid infestations.
\end{abstract}

\section{Introduction}

The summers in the highlands of Himachal Pradesh (India) representing temperate areas are quite cool as compared to the lower areas of the state and other parts of the country which experience extreme ambient conditions with temperature between 45 to $50^{\circ} \mathrm{C}$. The cooler climatic conditions with intense sunlight favour plant growth during this time and provide ideal conditions for growing off-season vegetables including local and exotic crucifers. At this same time, crucifer vegetables cannot be grown in other areas. Therefore, the farmers of this temperate belt can get good remunerative price for their produce. One of the prominent factors that discouraged the farmers to grow off-season crucifers was the poor road connectivity. Pea and potato are two commercial crops grown over an area of 1782 and 747 ha, respectively in the valley (Anon. 2011a).

However, in recent years, the road connectivity has improved and it has encouraged the farmers to diversify from the monoculture of pea and potato. Consequently, farmers who grew crucifer crops earlier for domestic consumption have started growing them on larger scale and sending to the markets in the lower areas including Chandigarh and Delhi. The area under crucifer crops has increased from 26 ha (2005-06) to 102 ha (2009-10) representing an increase of 292.3 per cent (Anon. 2011a). It is further likely to increase exponentially leading to much needed diversification in present agro-ecosystem.

A number of insect pests have been observed to attack crucifer crops in the valley during all the crop growth stages. Amongst these, cabbage aphid, Brevicoryne brassicae L. (Homoptera: Aphididae) is an important pest attacking cabbage (Anon. 2011b). The farmers use any insecticide supplied by the Department of Agriculture, Government of Himachal Pradesh on subsidized rates to control it. Some commercial farmers also use un-recommended insecticides available in the market (Badenes and Shelton 2006). This injudicious use of insecticide harms the natural enemy complex present in the agro-ecosystem. Excessive sprays also reduce the quality of the produce with harmful effects on the health of consumers.

*Present address: CSK HPKV, Krishi Vigyan Kendra, Una at Rampur, Himachal Pradesh (India)-174303.

<sanjayhpau@yahoo.com>. 
Therefore, the present studies were undertaken to evaluate the influence of $B$. brassicae incidence on the yield of marketable cabbage heads under protected and unprotected crop conditions so that insecticides sprays may be initiated at the right time. It would help in avoiding excessive sprays and preventing injudicious use of insecticides. Malathion 50 EC (0.05\%), Endosulfan 35 EC $(0.035 \%)$ and freshly prepared neem seed kernel extract (NSKE) $(0.0125 \%)$ arranged in different spray regimes were used to protect the crop from B. brassicae infestation.

\section{Materials and Methods}

Experiments were conducted at the research farm of Highland Agricultural Research and Extension Centre, Kukumseri, Lahaul and Spiti, in the dry temperate zone of Himachal Pradesh (2772 $\mathrm{m}$ amsl). Experiment was done in RBD with three replications during summer seasons of 2008 and 2009. Each plot measured $3.0 \times 2.25 \mathrm{~m}^{2}$ and the cabbage seedlings (cv-Golden Acre) were transplanted in the first week of May at 60 and $45 \mathrm{~cm}$ distance between plant to plant and row to row, respectively. The recommended agronomic practices except plant protection measures against the pests were followed in raising the crop (Anon. 2009). After transplanting, the crop was regularly monitored for cutworm incidence. The cutworms were manually removed from the root zone of the affected plants. Only manual weeding was done.

The crop was regularly monitored for initial infestation by $B$. brassicae. The protective sprays were initiated at 20 to 25 per cent plant infestation and repeated after 14 days. Seven spray regimes were used for crop protection in the present studies. Fresh NSKE was prepared by soaking $50 \mathrm{~g}$ broken neem seed kernels in one litre water for $24 \mathrm{hrs}$.

Data were recorded on population of $B$. brassicae, plant infestation and yield of marketable cabbage heads. The data recording on population and infestation commenced with the onset of pest activity in the first fortnight of June. Initially the data were recorded at weekly intervals until plant infestation reached 20 to 25 per cent. After this, the sprays were initiated and the data were recorded one day before and 14 days after each spray. Five plants per plot were selected at random for recording the population of $B$. brassicae. All the leaves of plant were thoroughly examined for the presence of aphid nymphs. The nymphs present on all the leaves of a plant were counted and aggregated to work out the final count for that plant. Then mean number of nymphs per plant was worked out. For plant infestation, all plants in a plot were observed for the presence of nymphs of B. brassicae. A plant was considered as infested even if a single nymph was present on it. The per cent plant infestation was calculated as:

Plant infestation $(\%)=($ Number of infested plants per plot/Total number of plants per plot $) \times 100$

Data on the yield of marketable cabbage heads obtained from each plot were recorded at each harvesting. Yields of respective plots were summed up after final harvesting to get the total yield for each plot. The data of mean aphid population, plant infestation and yield of marketable cabbage heads for all the plots were computed for subjecting it to statistical analysis. The data on plant infestation were analysed after arc sine transformations and the data on pest population and yield of marketable cabbage heads were analysed after square root transformations for the two years separately using CPCS1 software.

The yield of marketable cabbage heads was linearly regressed on aphid population as well as plant infestation to obtain regression equations and coefficients of determination $\left(\mathrm{R}^{2}\right)$. The regression equations estimated the nature of relationship between the yield of marketable cabbage heads and aphid population/plant infestation. The $\mathrm{R}^{2}$ values were useful in explaining the extent of variation in yield as influenced by aphid population and plant infestation. 


\section{Results and Discussion}

The data of B. brassicae population and plant infestation are presented in Tables 1 and 2, respectively. The yields of marketable cabbage heads are given in Table 3 .

Table 1. Population of Brevicoryne brassicae on cabbage under protected and unprotected conditions at specified intervals.

\begin{tabular}{llll}
\hline \multirow{2}{*}{ Protective spray regime } & \multicolumn{3}{c}{$\begin{array}{c}\text { Population of Brevicoryne brassicae } \\
\text { (Mean number of nymphs/ plant) }\end{array}$} \\
\cline { 2 - 4 } NSKE-NSKE & $44.00(6.17)$ & $33.20(5.39)^{\mathrm{cd}}$ & $14 \mathrm{DAS}_{2}{ }^{4}$ \\
\hline \multirow{2}{*}{ NSKE-endosulfan } & $30.93(5.47)$ & $59.33(7.69)^{\mathrm{b}}$ & $37.47(6.16)^{\mathrm{b}}$ \\
& $19.00(4.18)$ & $11.67(3.42)^{\mathrm{abcd}}$ & $0.30(1.13)^{\mathrm{a}}$ \\
NSKE-malathion & $49.33(7.09)$ & $68.67(8.30)^{\mathrm{bc}}$ & $2.20(1.78)^{\mathrm{a}}$ \\
Endosulfan-malathion & $38.93(5.92)$ & $20.33(4.37)^{\mathrm{bcd}}$ & $4.02(2.11)^{\mathrm{a}}$ \\
& $38.47(6.25)$ & $68.67(8.33)^{\mathrm{bc}}$ & $1.80(1.67)^{\mathrm{a}}$ \\
Malathion-endosulfan & $17.47(4.13)$ & $2.40(1.84)^{\mathrm{ab}}$ & $0.93(1.39)^{\mathrm{a}}$ \\
& $30.40(5.60)$ & $4.93(2.42)^{\mathrm{a}}$ & $0.53(1.24)^{\mathrm{a}}$ \\
Endosulfan-endosulfan & $62.07(7.61)$ & $11.67(3.33)^{\mathrm{abcd}}$ & $0.17(1.08)^{\mathrm{a}}$ \\
& $46.73(6.79)$ & $3.27(2.05)^{\mathrm{a}}$ & $0.42(1.18)^{\mathrm{a}}$ \\
Malathion-malathion & $21.07(4.67)$ & $7.13(2.83)^{\mathrm{abc}}$ & $0.70(1.26)^{\mathrm{a}}$ \\
& $38.27(6.15)$ & $4.13(2.25)^{\mathrm{a}}$ & $0.37(1.15)^{\mathrm{a}}$ \\
Unprotected & $13.13(3.64)$ & $1.47(1.57)^{\mathrm{a}}$ & $0.55(1.23)^{\mathrm{a}}$ \\
& $50.40(7.10)$ & $1.27(1.50)^{\mathrm{a}}$ & $0.75(1.31)^{\mathrm{a}}$ \\
& $38.33(6.11)$ & $37.33(5.99)^{\mathrm{d}}$ & $66.13(7.88)^{\mathrm{c}}$ \\
\hline CD (p = 0.05) & $43.40(6.65)$ & $86.00(9.32)^{\mathrm{c}}$ & $46.33(6.69)^{\mathrm{b}}$ \\
\hline & $\mathrm{NS}$ & 2.68 & 2.46 \\
& $\mathrm{NS}$ & 1.26 & 1.29 \\
\hline
\end{tabular}

${ }^{1}$ Figures in the parentheses are square root transformed means; ${ }^{2}$ Figures in the first and second lines pertain to years 2008 and 2009, respectively; ${ }^{3}$ Pre-treatment; ${ }^{4}$ Days after first/second spray.

The yield of marketable cabbage heads had negative and strong correlation with $B$. brassicae population at $14 \mathrm{DAS}_{1}$ and $14 \mathrm{DAS}_{2}$ as revealed by regression equations and coefficients of determination $\left(\mathrm{R}^{2}\right)$. While, it was weakly correlated to aphid populations at pre-treatment. The $\mathrm{R}^{2}$ values between yield of marketable cabbage heads and aphid population at pre-treatment, $14 \mathrm{DAS}_{1}$ and $14 \mathrm{DAS}_{2}$ were $0.085,0.893,0.738$, respectively in 2008 and $0.025,0.808,0.825$, respectively in 2009 (Fig. 1).

As in case of aphid population, the yield of marketable cabbage heads was also observed to be strongly and negatively correlated to plant infestations at $14 \mathrm{DAS}_{1}$ and $14 \mathrm{DAS}_{2}$ and weakly at pre-treatment in both years. The $\mathrm{R}^{2}$ values were $0.192,0.001$ at pre-treatment; $0.896,0.738$ at 14 $\mathrm{DAS}_{1} ; 0.593,0.854$ at $14 \mathrm{DAS}_{2}$ in two years, respectively (Fig. 2).

Strong correlation between yield of marketable cabbage heads and aphid population at 14 $\mathrm{DAS}_{1}$ and $14 \mathrm{DAS}_{2}$ implied that build up of aphid population during later stages of crop growth significantly affected the final yield of marketable cabbage heads. One unit increase in aphid population at $14 \mathrm{DAS}_{1}$ and $14 \mathrm{DAS}_{2}$ accounted for 80.8 to 89.3 per cent and 73.8 to 82.5 per cent reduction in yield of marketable cabbage heads, respectively in two years. Whereas, weak 
correlation between yields of marketable cabbage heads and aphid populations at pre-treatment indicated that early aphid population had no significant impact on yield of marketable cabbage heads as it explained only a maximum 8.5 per cent reduction in yield for every one unit increase in mean aphid population.

Table 2. Cabbage infestation by Brevicoryne brassicae under protected and unprotected conditions at specified intervals.

\begin{tabular}{llll}
\hline Protective spray regime & \multicolumn{3}{c}{ Plant infestation by Brevicoryne brassicae $^{1,2}(\%)$} \\
\cline { 2 - 4 } & PTM $^{3}$ & $14 \mathrm{DAS}_{1}{ }^{4}$ & $14 \mathrm{DAS}_{2}{ }^{4}$ \\
\hline NSKE-NSKE & $17.33(24.56)$ & $12.00(20.08)^{\mathrm{bc}}$ & $10.67(18.98)^{\mathrm{b}}$ \\
NSKE-endosulfan & $21.33(27.48)$ & $33.33(35.20)^{\mathrm{b}}$ & $44.00(41.52)^{\mathrm{c}}$ \\
& $16.00(23.46)$ & $13.33(21.19)^{\mathrm{c}}$ & $1.33(3.84)^{\mathrm{a}}$ \\
NSKE-malathion & $21.33(27.35)$ & $36.00(36.84)^{\mathrm{b}}$ & $9.33(17.70)^{\mathrm{b}}$ \\
& $13.33(21.08)$ & $10.67(18.81)^{\mathrm{bc}}$ & $1.33(3.84)^{\mathrm{a}}$ \\
Endosulfan-malathion & $17.33(24.56)$ & $32.00(34.41)^{\mathrm{b}}$ & $1.33(3.84)^{\mathrm{a}}$ \\
& $13.33(21.36)$ & $2.67(7.69)^{\mathrm{a}}$ & $2.67(5.47)^{\mathrm{a}}$ \\
Malathion-endosulfan & $21.33(27.35)$ & $2.67(5.47)^{\mathrm{a}}$ & $1.33(3.84)^{\mathrm{a}}$ \\
& $18.67(25.49)$ & $1.33(3.84)^{\mathrm{a}}$ & $2.67(5.47)^{\mathrm{a}}$ \\
Endosulfan-endosulfan & $20.00(26.48)$ & $1.33(3.84)^{\mathrm{a}}$ & $1.33(3.84)^{\mathrm{a}}$ \\
& $18.67(25.56)$ & $4.00(9.32)^{\mathrm{ab}}$ & $1.33(3.84)^{\mathrm{a}}$ \\
Malathion-malathion & $18.67(25.38)$ & $4.00(9.32)^{\mathrm{a}}$ & $1.33(3.84)^{\mathrm{a}}$ \\
& $18.67(25.56)$ & $4.00(9.32)^{\mathrm{ab}}$ & $1.33(3.84)^{\mathrm{a}}$ \\
Unprotected & $18.67(25.56)$ & $2.67(7.69)^{\mathrm{a}}$ & $1.33(3.84)^{\mathrm{a}}$ \\
& $13.33(21.36)$ & $22.67(28.40)^{\mathrm{c}}$ & $50.67(45.36)^{\mathrm{c}}$ \\
\hline CD (p = 0.05) & $18.67(25.49)$ & $32.00(34.26)^{\mathrm{b}}$ & $46.67(43.06)^{\mathrm{c}}$ \\
\hline & $\mathrm{NS}$ & 10.92 & 12.75 \\
\hline
\end{tabular}

${ }^{1}$ Figures in the parentheses are arc sine transformed means; ${ }^{2}$ Figures in the first and second lines pertain to years 2008 and 2009, respectively; ${ }^{3}$ Pre-treatment; ${ }^{4}$ Days after first/second spray.

Table 3. Yield of marketable cabbage heads under different spray regimes.

\begin{tabular}{lcc}
\hline Protective spray regime & \multicolumn{2}{c}{ Yield of marketable cabbage heads $^{1}$ (tonnes/ ha) } \\
\cline { 2 - 3 } & 2008 & 2009 \\
\hline NSKE-NSKE & $13.37(11.60)^{\mathrm{c}}$ & $13.17(11.52)^{\mathrm{c}}$ \\
NSKE-endosulfan & $17.23(13.16)^{\mathrm{b}}$ & $17.67(13.33)^{\mathrm{b}}$ \\
NSKE-malathion & $18.10(13.49)^{\mathrm{b}}$ & $18.17(13.52)^{\mathrm{b}}$ \\
Endosulfan-malathion & $22.77(15.12)^{\mathrm{a}}$ & $22.67(15.09)^{\mathrm{a}}$ \\
Malathion-endosulfan & $22.57(15.05)^{\mathrm{a}}$ & $22.70(15.10)^{\mathrm{a}}$ \\
Endosulfan-endosulfan & $22.40(15.00)^{\mathrm{a}}$ & $22.27(14.96)^{\mathrm{a}}$ \\
Malathion-malathion & $23.07(15.22)^{\mathrm{a}}$ & $22.77(15.12)^{\mathrm{a}}$ \\
Unprotected & $10.60(10.34)^{\mathrm{d}}$ & $11.33(10.69)^{\mathrm{d}}$ \\
$\mathrm{CD}(\mathrm{p}=0.05)$ & 0.46 & 0.38 \\
\hline
\end{tabular}

${ }^{1}$ Figures in the parentheses are square root transformed means. 

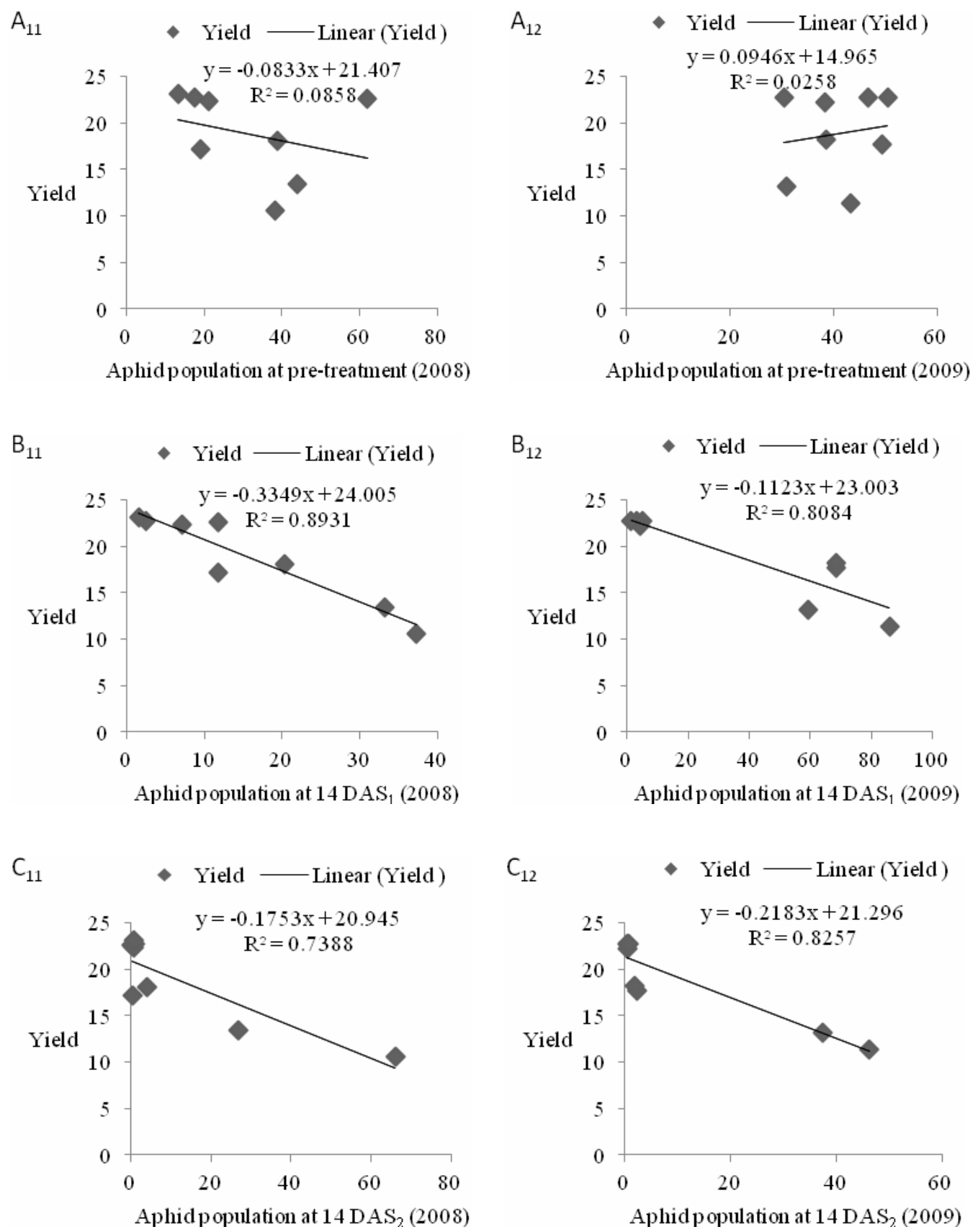

Fig. 1. Estimated linear relationship between yield of marketable cabbage heads (y) and population of cabbage aphid $(\mathrm{x})\left(\mathrm{A}_{11}-\mathrm{C}_{12}\right)$. 
$\mathrm{A}_{21}$

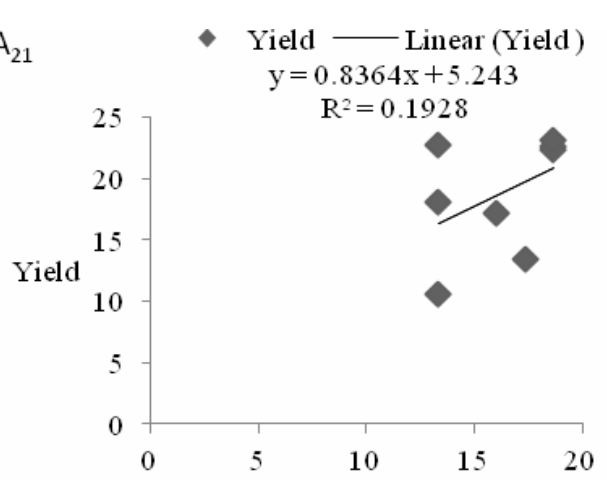

Plant infestation at pre-treatment (2008)
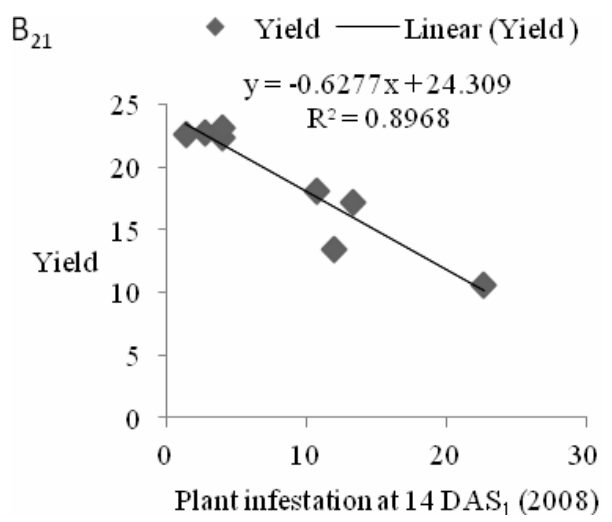

$\mathrm{C}_{21}$

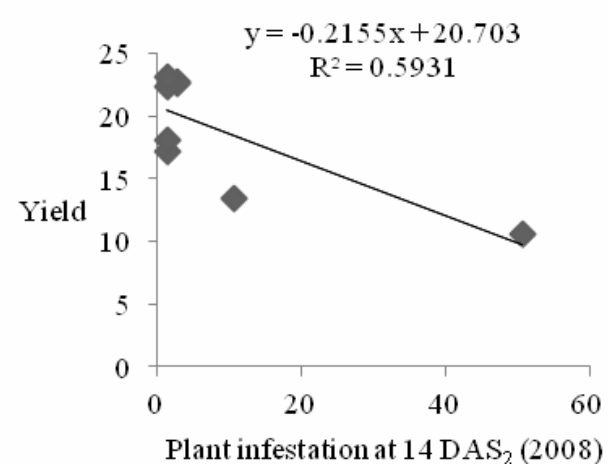

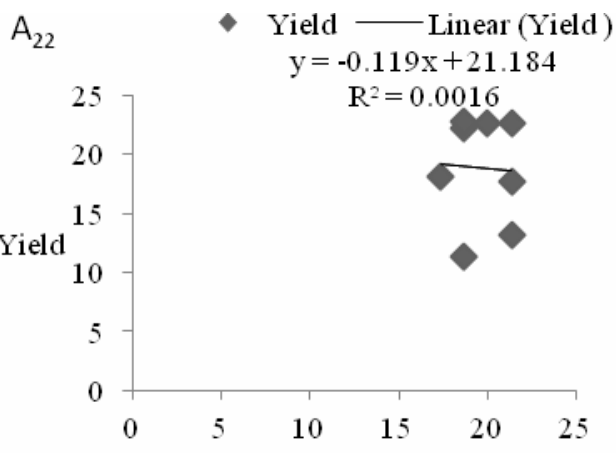

Plant infestation at pre-treatment (2009)

$\mathrm{B}_{22}$

- Yield Linear (Yield)

$y=-0.2395 x+23.155$

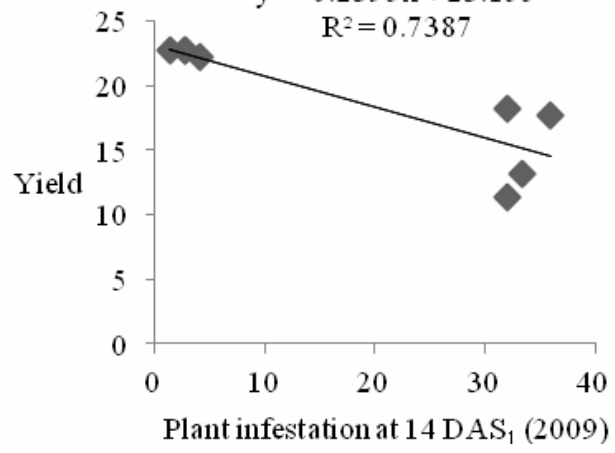

$\mathrm{C}_{22}$

- Yield Linear (Yield)

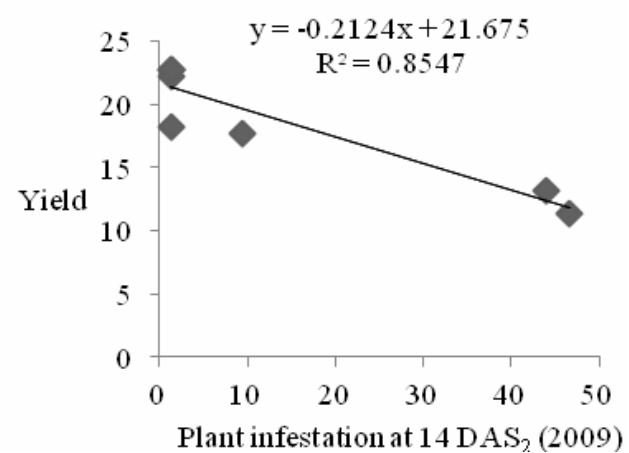

Fig. 2. Estimated linear relationship between yield of marketable cabbage heads (y) and plant infestation by cabbage aphid (x) $\left(\mathrm{A}_{21}-\mathrm{C}_{22}\right)$. 
Similarly, late stage plant infestations were more capable in reducing the yield of marketable cabbage head as indicated by high $\mathrm{R}^{2}$ values of $0.896,0.738$ and $0.593,0.854$ obtained between yield and plant infestations at $14 \mathrm{DAS}_{1}$ and $14 \mathrm{DAS}_{2}$ in two years, respectively. Every one per cent increase in plant infestation at $14 \mathrm{DAS}_{1}$ and $14 \mathrm{DAS}_{2}$ could reduce the yield of marketable cabbage heads by 73.8 to 89.6 per cent, respectively in 2008 and by 59.3 to 85.4 per cent, respectively in 2009. As in case of aphid population, the week correlation between yield of marketable cabbage heads and plant infestation at pre-treatment $\left(\mathrm{R}^{2}=0.192,0.001\right.$ in 2008 and 2009 , respectively) indicated that early aphid infestations had no significant effect on the final yield of marketable cabbage heads. Every one per cent increase in plant infestation at pre treatment accounted for a maximum 1.92 per cent reduction in yield of marketable cabbage heads. Therefore, pesticides sprays on these early infestations by B. brassicae might be avoided to promote activity of natural enemies present in the agro-ecosystem, which could check these early infestations. On the other hand, late infestations of $B$. brassicae should be effectively controlled to prevent economic losses.

Nieto et al. (2006) noted that early arriving cabbage aphids were less likely to infest a broccoli (Brassica oleracea L.) head and recommended to develop management practices that encourage the early establishment of natural enemies. Other farmer friendly management options like use of yellow sticky traps or yellow water pan traps for trapping adult aphids, sprinkler system of irrigation instead of flood irrigation, removal and burial of aphid infested leaves, growing crucifer crops with leguminous living mulch using red clover and white clover as cover crop might also be promoted to control early $B$. brassicae menace. These practices would improve the overall health of agro-ecosystem, water use efficiency and economics of crop cultivation. Contrary to present results, Brown et al. (1999) reported that very late cabbage aphid infestations in two mustard species (Brassica juncea L. and Sinapis alba L.) did not have major effect on seed yield, but insect attack including that by cabbage aphid on the two canola species (B. napus L. and B. rapa L.) significantly reduced oil content although oil quality (indicated by fatty acid profile) was not affected. No major reduction in seed yield of mustard by very late infestation might be due to non palatability of nearly mature plants to cabbage aphid. Consequently, the aphid population might not have built up to sufficient levels so as to cause economic losses. Whereas, losses in oil content by late stage insect attack did seem to be directly correlated to insect infestations. Therefore, these earlier results obliquely corroborated the present findings which suggested that it was very important to manage the late stage aphid infestation to get higher monetary returns. Knowledge of the often complex relationship between insect populations and their effects on the yield-forming processes of crops is useful for assessing pest status and for devising methods of minimising the effects of infestation on yield. Investigations into the yield-forming processes of un-attacked crops can often provide useful insights into the likely effect of insect injuries on yield (Bardner and Fletcher 1974).

\section{References}

Anonymous 2009. Sabjiyon ke liye sampooran sifarshein (Complete recommendations for vegetables' cultivation). Directorate of Extension Education, CSK Himachal Pradesh Krishi Vishvavidyalaya Palampur, Himachal Pradesh, India. pp. 203.

Anonymous 2011a. Statistical outline of Himachal Pradesh. pp. 202.

Anonymous 2011b. Annual Report. Department of Entomology, CSK Himachal Pradesh Krishi Vishvavidyalaya Palampur, Himachal Pradesh, India. pp. 63.

Badenes PFR and Shelton AM 2006. Pest management and other agricultural practices among farmers growing cruciferous vegetables in the Central and Western highlands of Kenya and the Western Himalayas of India. Int. J. Pest Management 52: 303-315. 
Bardner R and Fletcher KE 1974. Insect infestations and their effects on the growth and yield of field crops: A review. Bull. Entomol. Res. 64: 141-160.

Brown J, McCaffrey JP, Harmon BL, Davis JB, Brown AP and Erickson DA 1999. Effect of late season insect infestation on yield, yield components and oil quality of Brassica napus, B. rapa, B. juncea and Sinapis alba in the Pacific Northwest region of the United States. J. Agric. Sci. 132: 281-288.

Nieto DJ, Shennan C, Settle WH, O'Malley R, Bros S and Honda JY 2006. How natural enemies and cabbage aphid (Brevicoryne brassicae L.) population dynamics affect organic broccoli harvest. Environ. Entomol. 35: 94-101.

(Manuscript received on 12 December, 2012; revised on 14 December, 2014) 